\title{
Usefulness of chronic total occlusion devices and techniques in other complex lesion subsets
}

\author{
Lazzaro Paraggio, Francesco Burzotta, Cristina Aurigemma, Carlo Trani \\ Institute of Cardiology, Università Cattolica del Sacro Cuore, Fondazione Policlinico Universitario A. Gemelli, IRCCS, Rome \\ 00168, Italy.
}

Correspondence to: Dr. Francesco Burzotta, Institute of Cardiology, Università Cattolica del Sacro Cuore, Fondazione Policlinico Universitario A. Gemelli, IRCCS, Rome 00168, Italy. E-mail: francescoburzotta@gmail.com

How to cite this article: Paraggio L, Burzotta F, Aurigemma C, Trani C. Usefulness of chronic total occlusion devices and techniques in other complex lesion subsets. Vessel Plus 2019;3:12. http://dx.doi.org/10.20517/2574-1209.2018.72

Received: 9 Nov 2018 First Decision: 21 Jan 2019 Revised: 11 Feb 2019 Accepted: 12 Mar 2019 Published: 19 Apr 2019

Science Editors: Alfredo R. Galassi, Marouane Boukhris Copy Editor: Cai-Hong Wang Production Editor: Huan-Liang Wu

\begin{abstract}
Percutaneous coronary interventions ( $\mathrm{PCI}$ ) in chronic total occlusion (CTO) have been for long time considered as "last frontier" in interventional cardiology. Among the different subset of complex targets for $\mathrm{PCl}, \mathrm{CTO}$ lesions represent a challenge for the interventional cardiologist. CTO techniques and devices have evolved in last few years together with the training of specialized interventional cardiologist in such complex field. All these factors have markedly increased procedural success of CTO procedures and have the potential to be applied in other settings. In this paper, we provide an update on the technical aspects and the devices developed for CTO PCls that can be applied in complex PCI on non-CTO lesions.
\end{abstract}

Keywords: Chronic total occlusion, complex percutaneous coronary interventions, complications, interventional devices

\section{INTRODUCTION}

Chronic total occlusion (CTO) lesions are defined as a coronary lesion with Thrombolysis In Myocardial Infarction grade 0 flow distal to the occluded segment and, although often difficult to determine, clinical evidence of occlusion duration more than 3 months ${ }^{[1]}$.

CTO represent the most technically challenging procedure subset for the interventional cardiologists. They show a high prevalence between patients referred for coronary angiography in various real-world registries, with an incidence increasing with age ${ }^{[2,3]}$. Some recent observational studies have shed a new

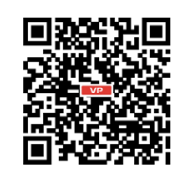


Table 1. American Heart Association/American College of Cardiology lesion classification system

\begin{tabular}{|c|c|c|}
\hline \multicolumn{3}{|c|}{ Anatomic risk groups } \\
\hline Low risk & Moderate risk & High risk \\
\hline Discrete (length $<10 \mathrm{~mm}$ ) & Tubular (length 10-20 mm) & Diffuse (length $<20 \mathrm{~mm}$ ) \\
\hline Concentric & Eccentric & Excessive tortuosity of proximal segment \\
\hline Readily accessible & Moderate tortuosity of proximal segment & Extremely angulated segments $>90^{\circ}$ \\
\hline Nonangulated segment $\left(<45^{\circ}\right)$ & Moderately angulated segment $\left(>45^{\circ},<90^{\circ}\right)$ & Total occlusions $>3$ months old and/or bridging \\
\hline Smooth contour & Irregular contour & collaterals \\
\hline Little or no calcification & Moderate or heavy calcification & Inability to protect major side branches \\
\hline Less than totally occlusive & Total occlusions $<3$ months old & Degenerated vein grafts with friable lesions \\
\hline Not ostial in location & Ostial in location & \\
\hline No major side branch involvement & Bifurcation lesions requiring double guidewires & \\
\hline Absence of thrombus & Some thrombus present & \\
\hline
\end{tabular}

light about CTO procedures demonstrating a clinical benefit in term of reduced angina symptoms ${ }^{[4]}$, improved left ventricular ejection fraction ${ }^{[5]}$ and improved long term survival ${ }^{[6]}$. However, when looking to recent randomized clinical trials, there are still some concerns about effective clinical impact of CTO revascuarization, showing conflicting results ${ }^{[7-10]}$.

Above all these clinical and prognostic considerations, only in the last few years, the developing of new techniques and new devices and guidewires has raised the procedural success to near $90 \%{ }^{[11-15]}$ in experienced centers. However, observational reports still showed that CTO procedural success rate is lower in less skilled hands, reaching in some cases only $70 \%{ }^{[12]}$. Following technical advancement and procedural increased success, interventional cardiologists have been recently more involved in CTO procedures. Hence, it is now advisable for the interventional cardiologist to follow specific training programs and to consider on site proctoring before starting to perform CTO procedures. Moreover, operators involved in such courses and on-site CTO programs could improve their learning curve even in complex percutaneous coronary interventions (PCI), bringing their experience about CTO devices and techniques to everyday practice.

Hence, in this review, we focus the attention on specific insights on CTO devices and techniques, which could enhance interventional cardiologist capability to overcome many challenges and complications encountered during daily PCI.

\section{PLANNING THE PROCEDURE: WEIGH THE PROS AND CONS}

Accurate angiographic review with complete quantification of possible hazard during the procedure remains a cornerstone of successful CTO PCI. In this context, dual injection angiography should be performed in all cases except in the complete absence of contralateral collaterals. A complete evaluation of CTO lesion characteristic before the procedure is the key for the success.

A first extensive evaluation of anatomic predictors of PCI success was reported in AHA/ACC Guidelines for Percutaneous Interventions [Table 1] ${ }^{[16]}$. However, regarding CTO procedures, many scores have been proposed, but the most commonly used for its simplicity in identifying main characteristics that may impact procedural success is the "J-CTO" score ${ }^{[17]}$. Patients with higher J-CTO score have significantly lower success rate. The four angiographic parameters of this score are: (1) proximal cap location and morphology, with a clearly defined and "tapered" proximal cap favoring antegrade approach; (2) lesion length, with a value $>20 \mathrm{~mm}$ clearly more challenging to cross; (3) calcification; (4) bending $>45^{\circ}$ within CTO lesions, which lower procedural success.

More recently many other scores, such as RECHARGE CTO score ${ }^{[14]}$ and PROGRESS CTO score ${ }^{[15]}$, have demonstrated a similar predictive ability of CTO procedural success when compared with J-CTO score. 
The above described score tools are very useful to guide clinical and procedural decision during CTO procedures. In addition, they could be very helpful when planning complex PCI as they underlined all angiographic and clinical predictors of every PCI technical success.

\section{CAN COMPLEX PCI AND CTO PROCEDURES FIT TRANSRADIAL APPROACH?}

In usual PCI setting $6 \mathrm{~F}$ Guiding Catheter (GC) is enough to obtain a complete procedural success in the vast majority of cases. However, CTO lesions could better be afforded using large ( $7 \mathrm{~F}$ or $8 \mathrm{~F}$ ) GC in order to obtain larger inner space together with higher back-up support and stability. In last decade, this strategy was almost exclusively performed by transfemoral approach. However, the selection of radial arteries as vascular access for complex PCI has substantially grown in the last ten years as several studies have demonstrated a marked reduction of access site-related bleedings ${ }^{[18]}$. Recently, several technical improvements in PCI's materials have boosted utilization of radial approach even in more complex interventions, such as CTO procedures, also adding the option of hybrid vascular approach $(6 \mathrm{~F}$ radial access for contralateral injection and $7 \mathrm{~F}$ or $8 \mathrm{~F}$ for antegrade/retrograde approach) ${ }^{[19]}$. First, a new family of GC, called "Sheathless" (first available type: Eucath, Asahi, Japan), has been introduced. The "Sheathless" GC has a highly hydrophilic coating and can be inserted without a sheath thus showing an increased inner lumen when compared to standard GC ( $6.5 \mathrm{~F}$ vs. $6 \mathrm{~F}$ or $7.5 \mathrm{~F}$ vs. $7 \mathrm{~F})$. More recently, a brand-new sheath, called "Slender" (Terumo, Tokyo, Japan), has been produced and showed an increased inner lumen despite an outer diameter still in the range of radial compatibility. Therefore, in the setting of complex PCI, a 6-in-7 F "Slender" sheath could be easily used to insert a 7F GC into radial artery thus combining technical feasibility with lower vascular access related complications.

The development of such devices have progressively make radial approach more common during CTO procedures. Indeed, in such procedures, the need for larger GC is essential as only two microcatheters or one microcatheter and a monorail balloon fit together into $6 \mathrm{~F} \mathrm{GC}$, while all frequently used devices can be only inserted alone.

In the setting of CTO intervention and more extensively in all PCIs, material compatibility is a critical issue and operators should focus their attention on materials' compatibility, considering also that same material (for example same size of semi-compliant balloon) of different manufactures may have different diameter. Therefore, a careful procedure planning which includes a tailored selection of radial equipments may help safely carry on PCI through radial approach.

\section{GUIDING CATHETER AND MOTHER-IN CHILD DEVICES: THE NEED FOR MORE SUPPORT}

When planning a PCI, one of the first thing to decide is the GC you would use to obtain enough backup and support to perform the procedure. In the setting of CTOs, a large (7 or 8 F) GC offers more support and greater inner diameter which allows insertion of such complex materials, even in combination (such as dual over-the-wire microcatheters) and now can be inserted by radial approach. In last few years, several techniques and materials have been developed to increase procedural support to overcome difficulties encountered in crossing CTO or complex lesions and delivering PCI materials.

Nowadays, the need for more support in CTO procedures could be afforded by two different strategies: usage of devices with improved backup force ("passive support") or techniques to directly enhance support ("active support").

The better way to enhance passive support is to choose a larger GC with more supportive backup curves. Therefore, Amplatz left GC for the right coronary artery and XB (eXtraBackup) or EBU GC for the left coronary artery are commonly used to improve backup. In order to avoid such complications, side holes are 


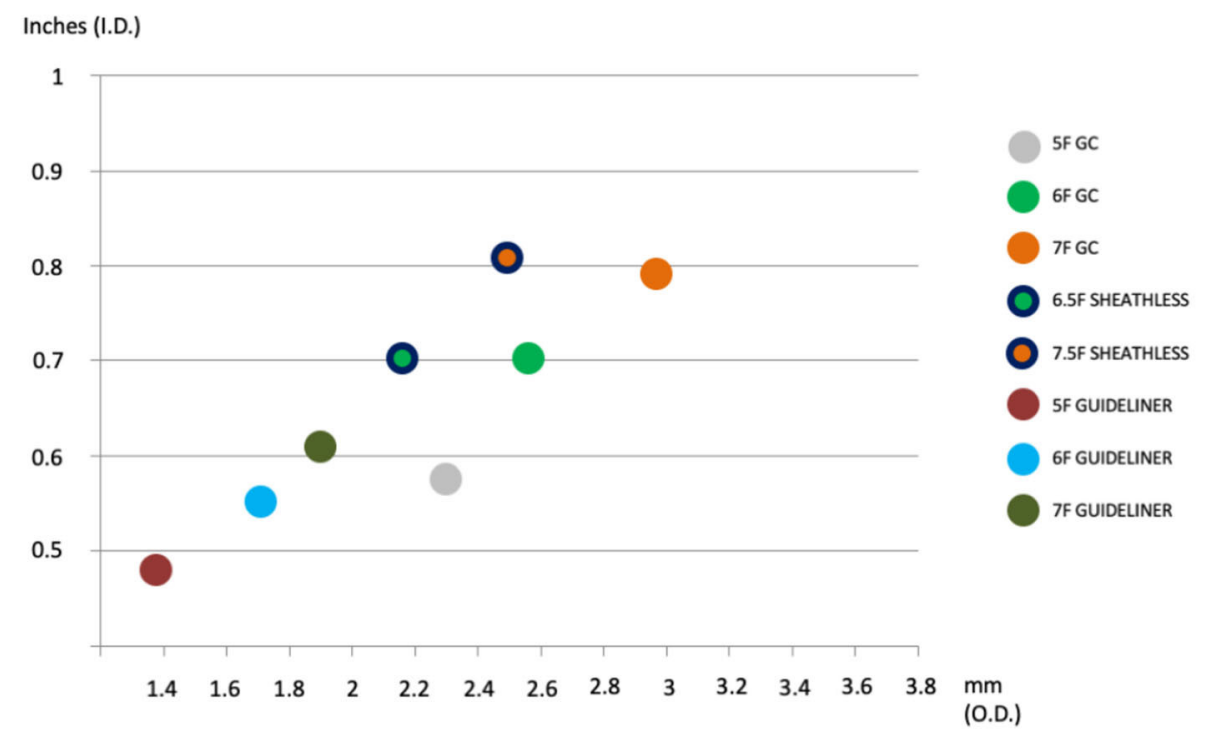

Figure 1. Comparative chart of different guiding catheter/GuideLiner systems which may be considered to perform percutaneous coronary interventions through radial approach. On X-axis outer diameter in millimeters; on Y-axis inner diameter in inches

often used to minimize dampening, but should not be used in unprotected left main as they can provide a false sense of security and cause severe ischemia. More recently, several mother-in-child devices have been introduced to maximize passive support during CTO and even complex PCI. The GuideLiner catheters (Vascular Solutions, Inc., MN, USA) were the first to be introduced in $2009^{[20]}$. All these devices are coaxial "mother and child" guiding catheter extension delivered through a standard guiding catheter on a monorail system with flexible distal extension and radiopaque markers near the distal tip. These characteristics, together with a tight design, allow deep intubation into the coronary arteries without slippage thus favoring the delivering of materials behind areas of narrowing or tortuosity, which could reduce GC backup [Figure 1].

On the other hand, active support could be improved with some techniques developed specifically for CTO procedures. A first unspecific option does exist and consist to perform a deep intubation of the GC. However, this old technique carries out a consistent risk of proximal vessel dissection and has been overcome by using mother-in-child devices. More recently, a new technique, called "mother-daughter-granddaughter" has been developed using a $6 \mathrm{~F}$ Guideliner into an $8 \mathrm{~F}$ Guideliner to allow navigation of very tortuous segments, such as saphenous graft, unfolding the equipment rather than pushing it. However, these technique should be handled more carefully as the risk of coronary dissection in very high.

The widespread use of $7 \mathrm{~F}$ or $8 \mathrm{~F} \mathrm{GC}$ led to the development of another active support option: the "anchoring balloon" technique ${ }^{[21]}$. Sometimes antegrade guidewire crossing of a CTO lesions is not followed by successful advance of microcatheters or balloon through the lesion. The first step of such technique is to wire a risk free side branch target before the lesion. Subsequently, inflating a balloon into the side branch provided a stable "anchor" which increase support to advance materials through CTO. This technique could be also useful in daily PCI procedures, in any case of difficult advancement of materials (such as balloon or stents) through tight or calcified lesion. More recently, some variations have been introduced to the original "anchoring balloon" technique. Out of these, the most used technique in daily PCI scenario is the distal mother-in-child devices anchoring ${ }^{[22]}$. In any case of difficult stent delivery, the mother-in-child device is advanced just before or even through the target lesion over a distally placed inflated balloon. Such balloon was then deinflated and withdrawn safely and the selected stent could be delivered at the site of the lesion [Figure 2].

In any case of highly complex PCI situations, the use of mother-in-child devices to increase passive support or the application of active support techniques could improve success rate, even in case of PCI that may have previously been considered technically unapproachable. 

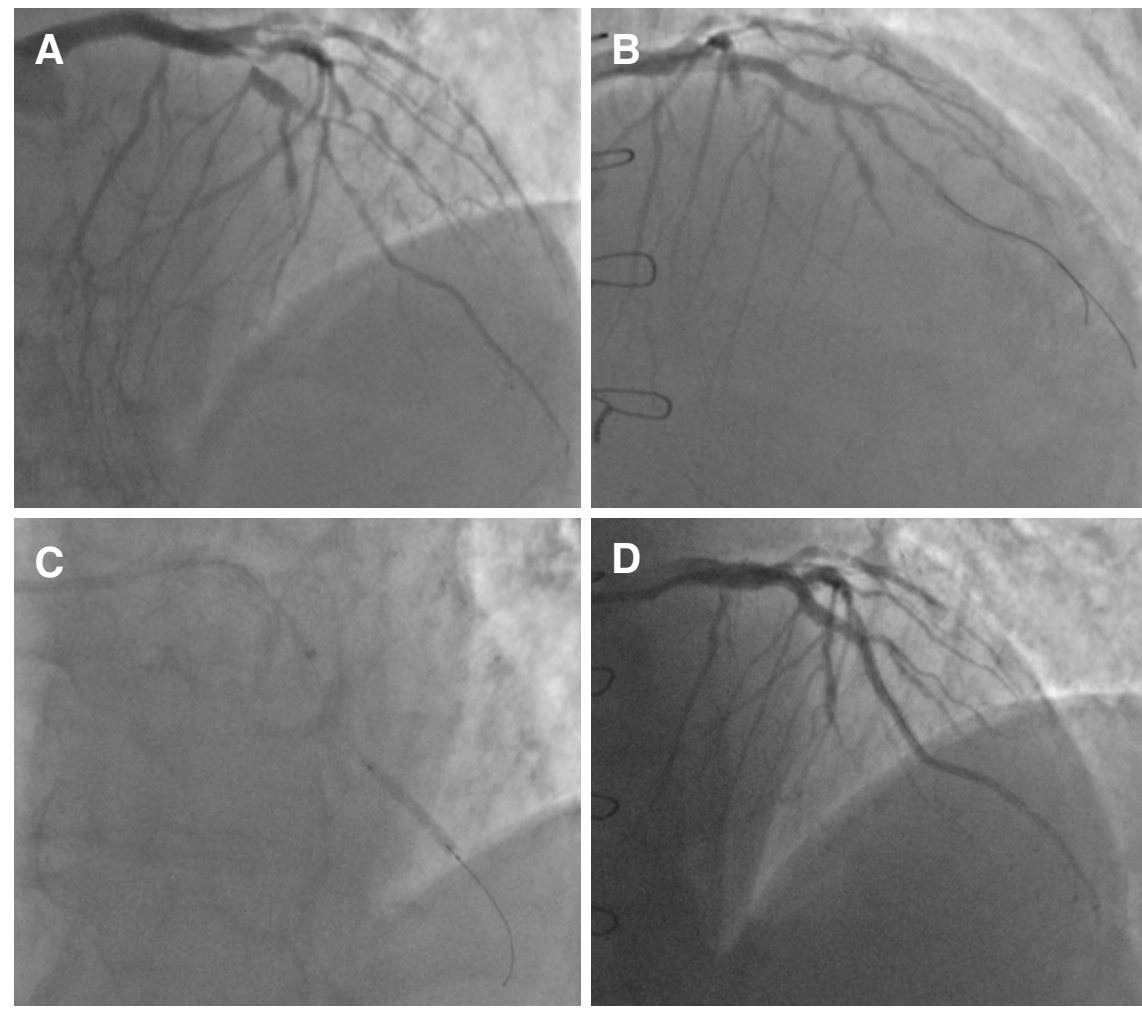

Figure 2. "Anchoring balloon" technique example. A: Basal angiographic assessment; B: angiographic evaluation after proximal stent implantation; C: GuideLiner delivery with distal anchoring balloon; D: final angiography after three more overlapping stents implantation

\section{GUIDEWIRES AND MICROCATHETERS: A BAG OF TRICKS}

The toolbox of CTO operators has rapidly increased over the last decade as new tools and equipments have been developed. A complete knowledge of such equipment is now essential for every interventional cardiologist in order to improve performance in everyday PCI.

Specialized CTO guidewires are now commonly available in every cathlab as they represent the key tool to afford antegrade crossing of CTO lesions. Indeed, antegrade wire escalation is the most commonly used technique to cross the lesion throughout the true vessel lumen and involves progressive utilization of guidewires with various stiffness and/or penetrating force. Moreover, with the development of global interest over CTO procedures, such guidewires have been extensively publicized even in international conventions and their characteristics are now familiar to every interventional cardiologist [Table 2]. In everyday practice, soft, tapered and polymer-jacketed wires, such as the Fielder family (Asahi Intecc, Japan), could be very useful to cross very narrowed lesions, especially in calcified vessels. In this setting, the polymeric coating together with the tapered tip of such guidewires may be helpful in navigating a narrow true lumen of a tortuous calcified vessel minimizing the risk of causing a dissection. However, routine use of polymer jacketed guidewires with higher tip weigh should be avoided in everyday practice. Beyond CTO guidewires, a new family of workhorse wires called Sion (Sion, Sion Blue and Sion Black; Asahi Intecc, Japan), characterized by a higher direction and torque response, have been developed and have showed such ability in retrograde collaterals crossing. Such wires are essentially driven by a new technology called "Composite Core": the parallel placement of a classic wire and a twist wire linked at the distal tip determine a more precise transmission of torque rotation. Such characteristics make Sion guidewires very useful in daily PCI in every case of difficult distal wire positioning in tortuous and/or calcified vessels and in bifurcation PCI when wiring or re-wiring of side branch is difficult due to a narrow angle. 
Table 2. Main characteristics of chronic total occlusion guidewires commonly used in daily percutaneous coronary interventions

\begin{tabular}{|c|c|c|c|c|c|c|}
\hline Family & Guidewire & $\begin{array}{l}\text { Shaft } \\
\text { coating }\end{array}$ & $\begin{array}{c}\text { Tip } \\
\text { coating }\end{array}$ & $\begin{array}{c}\text { Tip } \\
\text { diameter }\end{array}$ & Tip weight (g) & Main purpose \\
\hline \multirow[t]{2}{*}{$\begin{array}{l}\text { Fielder } \\
\text { (Asahi) }\end{array}$} & Fielder XT-A & Polymer jacketed & Hydrophilic & $\begin{array}{l}0.010 \\
\text { (tapered) }\end{array}$ & 1 & $\begin{array}{l}\text { Sliding of } \\
\text { microchannels }\end{array}$ \\
\hline & Fielder XT-R & Polymer jacketed & Hydrophilic & $\begin{array}{l}0.010 \\
\text { (tapered) }\end{array}$ & 0.6 & $\begin{array}{l}\text { Sliding of } \\
\text { microchannels }\end{array}$ \\
\hline \multirow[t]{3}{*}{$\begin{array}{l}\text { Sion } \\
\text { (Asahi) }\end{array}$} & Sion & Hydrophilic & Hydrophilic & 0.014 & 0.7 & $\begin{array}{l}\text { Navigation of } \\
\text { tortuous vessels }\end{array}$ \\
\hline & Sion Black & $\begin{array}{l}\text { Polymer } \\
\text { jacketed }\end{array}$ & Hydrophilic & 0.014 & 0.8 & $\begin{array}{l}\text { Surfing of small vessels } \\
\text { (collaterals) }\end{array}$ \\
\hline & Sion Blue & Hydrophilic & Hydrophobic & 0.014 & 0.5 & $\begin{array}{l}\text { Higher torque control for } \\
\text { vessel wiring }\end{array}$ \\
\hline \multirow[t]{3}{*}{$\begin{array}{l}\text { Sentai } \\
\text { (Boston Scientific) }\end{array}$} & Fighter & $\begin{array}{l}\text { Polymer } \\
\text { jacketed }\end{array}$ & Hydrophilic & $\begin{array}{l}0.009 \\
\text { (tapered) }\end{array}$ & 1.5 & $\begin{array}{l}\text { Sliding of } \\
\text { microchannels }\end{array}$ \\
\hline & Hornet & Hydrophilic & Hydrophilic & $\begin{array}{l}0.008 \\
\text { (tapered) }\end{array}$ & 1 & $\begin{array}{l}\text { Navigation of } \\
\text { microchannels }\end{array}$ \\
\hline & Samurai & Hydrophilic & $\begin{array}{l}\text { Moderated } \\
\text { Hydrophilic }\end{array}$ & 0.014 & 0.5 & $\begin{array}{l}\text { Higher torque control for } \\
\text { vessel wiring }\end{array}$ \\
\hline
\end{tabular}

A correct manipulation of CTO guidewires should always be performed using an over-the-wire system such as microcatheters. Main characteristics of such devices are summarized in Table 3. Among these, Finecross (Terumo, Tokyo, Japan) and Corsair Pro or Caravel (Asahi Intecc, Japan) are the most commonly used. The key role of microcatheter in CTO procedures could be summarized in three essential steps: (1) to safely place CTO guidewire just in front of the lesion; (2) to increase support and precision in CTO guidewire manipulation during antegrade crossing; (3) to allow guidewire exchange once the lesion has been crossed. All these steps could be used even in complex PCI procedures when a CTO dedicated guidewires is used to cross a heavy calcified and/or narrowed lesion as explained before or when a workhorse guidewire should be manipulated more precisely with facilitate torque in the tip response. Finally, microcatheters could be very useful to reduce guidewire kinking and prolapse while trying to cross a lesion immediately after a large side branch.

More recently, dual lumen microcatheters, such as Fineduo (Terumo, Tokyo, Japan), Crusade (Asahi Intecc, Japan), Twinpass (Vascular Solutions, USA) and NHancer RX (IMDS, The Netherlands), with both a rapid exchange and over-the-wire lumen, have been developed. During CTO procedures, dual lumen microcatheters are useful in some scenarios: (1) to allow a more precise engagement of the cap located at the level of a side branch (in antegrade approach) or located too close to the connection with interventional collateral (in retrograde approach); (2) to preserve side branch when a bifurcation is located into CTO body; (3) to perform "parallel wire" technique. In everyday practice, the employment of dual lumen microcatheters is increasing, as they could be very useful in bifurcation PCI to wire a side branch with difficult take-off angle or to re-wire side branches after crossover stenting ${ }^{[23]}$. Moreover, in any case of main vessel dissection without a protection guidewire into side branch during bifurcation PCI, a dual lumen microcatheter could help to wire the side branch limiting the risk of dissection expansion after second "free" guidewire advancement.

\section{BALLON UNCROSSABLE AND BALLOON UNDILATABLE LESIONS: PUSHING THE LIMIT}

After successful guidewire crossing, in $5 \%-10 \%$ the microcatheter is not able to cross CTO body ${ }^{[24]}$. This will usually occur in the highly calcified lesions, which are also challenging to cross with guidewires; however, even in simpler cases, this problem could arise unexpectedly. In this setting, some techniques may be adopted to increase support, such as "buddy wire", the employment of a mother-in-child system or the anchoring balloon technique, with uncertain results. In the past, in case of persisting uncrossability, the first widely used option was "grenadoplasty" (during which a small balloon is advanced as far as possible and then inflated at high pressures until it ruptures), with conflicting results in plaque modification. 
Table 3. Main characteristics of microcatheters

\begin{tabular}{|c|c|c|c|c|c|c|}
\hline Name & $\begin{array}{c}\text { Main } \\
\text { specification }\end{array}$ & Length (cm) & $\begin{array}{l}\text { Distal inner } \\
\text { lumen }\end{array}$ & $\begin{array}{l}\text { Entry tip } \\
\text { profile }\end{array}$ & $\begin{array}{l}\text { Crossing } \\
\text { profile }\end{array}$ & $\begin{array}{l}\text { Delivering } \\
\text { technique }\end{array}$ \\
\hline Finecross (Terumo) & $\begin{array}{l}\text { Single lumen, hydrophilic, } \\
\text { floppy tip }\end{array}$ & 130 or 150 & 0.018 & $1.8 \mathrm{Fr}$ & $1.8 \mathrm{Fr}$ & Push without rotation \\
\hline Corsair Pro (Asahi) & $\begin{array}{l}\text { Single lumen, moderated } \\
\text { hydrophilic, high support }\end{array}$ & 135 or 150 & 0.015 & $1.3 \mathrm{Fr}$ & $2.5 \mathrm{Fr}$ & $\begin{array}{l}\text { Counter-clockwise Rotation } \\
\text { (max } 10 \text { consecutive) }\end{array}$ \\
\hline Caravel (Asahi) & $\begin{array}{l}\text { Single lumen, highly hydrophilic } \\
\text { with low crossing profile }\end{array}$ & 135 or 150 & 0.016 & $1.4 \mathrm{Fr}$ & $1.9 \mathrm{Fr}$ & Push without rotation \\
\hline $\begin{array}{l}\text { Venture (Vascular } \\
\text { Solution) }\end{array}$ & $\begin{array}{l}\text { Single lumen with tip deflection } \\
\text { system of } 90^{\circ}\end{array}$ & 145 & 0.014 & $1.8 \mathrm{Fr}$ & $2.2 \mathrm{Fr}$ & Push without rotation \\
\hline Crusade (Asahi) & $\begin{array}{l}\text { Double lumen (OTW } 6.5 \mathrm{~mm} \\
\text { before tip) }\end{array}$ & 140 & 0.017 & $2.2 \mathrm{Fr}$ & $2.9 \mathrm{Fr}$ & Push without rotation \\
\hline $\begin{array}{l}\text { Twin Pass (Vascular } \\
\text { Solutions) }\end{array}$ & $\begin{array}{l}\text { Double lumen (OTW } 11 \text { mm } \\
\text { before tip) }\end{array}$ & 135 & 0.014 & $1.9 \mathrm{Fr}$ & $2.7 \mathrm{Fr}$ & Push without rotation \\
\hline FineDuo (Terumo) & $\begin{array}{l}\text { Double lumen (OTW } 6.5 \mathrm{~mm} \\
\text { before the tip) }\end{array}$ & 140 & 0.014 & $2.2 \mathrm{Fr}$ & $2.9 \mathrm{Fr}$ & Push without rotation \\
\hline
\end{tabular}

Nowadays, new low-profile rapid-exchange balloons, such as Tazuna (Terumo, Tokyo, Japan) and Ikazuchi (Kaneka Corporation, Japan) are available. The main feature of these ballons is the extremely low entry tip profile (between 0.015 and 0.017), lower than microcatheters, combined with a higher pushability given by the rapid-exchange system. Therefore, the successful crossing of the lesion with a balloon rather than microcatheter strongly increased in last few years. In cases of low-profile balloon failure, lesion modification techniques still represent a remarkable option, as plaque debulking subsequently facilitate balloon crossing. More specifically, if microcatheters successfully cross the lesion, the distal guidewire could be exchanged with a rotawire and rotational atherectomy ablation could be performed. Where available, $0.9 \mathrm{~mm}$ excimer laser atherectomy over a conventional guidewire is also an option. However, it must be highlighted that lesion modification techniques should be considered "last resort" measures where standard techniques have proved unsuccessful, as they could arise complications, such as coronary perforation and/or rupture and even devices entrapment with possible procedural failure or catastrophic consequences. More recently a new generation of microcatheters, the Turnpike family (Vascular Solutions, USA), show a higher capability in lesion crossing as they contain threads enabling a "screw-like" approach. However, these devices are quite aggressive and their employment is still relegated to CTO procedures. As expectable, most of these equipments are now widely used in everyday PCI in every case of lesion uncrossable (due to calcification, tortuosity or extremely narrowing) by a common semi-compliant balloon and have increased procedural success even in daily setting.

In CTO procedures, as in everyday PCI, an adequate predilation is essential before stent deployment. Among CTO lesions, undilatable lesions still represent a challenge for the interventional cardiologist. In the past, the first dedicated device designed to obtain successful dilation of calcified plaque was the Flextome ${ }^{\mathrm{TM}}$ Cutting Balloon ${ }^{\mathrm{TM}}$ Dilatation Device (Boston Scientific, USA). In such device, three or four microblades are mounted over a non-compliant balloon with several diameter and length. During the dilation, microblades create three or four plaque incisions facilitating subsequent expansion with conventional balloons. In last two decades, however, rotational atherectomy (Rotablator, Boston Scientific, USA) have represented the most remarkable option to obtain lesion modification and to facilitate balloon dilation. The diamond burr causes "differential cutting" of inelastic tissues preserving integrity of normal elastic segments while the high rotational speed (usually $>60,000 \mathrm{rpm}$ ) eliminate the contact between the burr and the arterial wall thus allowing crossing of tortuous segments without damage. Seldom, excimer laser coronary atherectomy could be used to perform plaque debulking by delivering of rapid ultraviolet B pulses to coronary lesion with subsequent tissue breakdown by photoacoustic mechanism. More recently, the idea to use local and high-energy lithotripsy waves for the treatment of coronary calcification lead to the development of a new dedicated device. Shockwave IVL system (Shockwave Medical Inc., USA) consist of a semicompliant, rapid-exchange balloon, connected to a pressure-waves generator by a cable. After lesion crossing, balloon 
is inflated at $4 \mathrm{~atm}$ and lithotripsy cicle in activated and pulses once per second for ten seconds (for a maximum of 8 repeatable cycles), thus cracking intraplaque calcium. This device has the potential to become a cornerstone in PCI, but only limited clinical data about outcome and safety are available ${ }^{[25]}$ and further randomized trials are needed. Another valuable option is the employment of recent developed high pressure, non-compliant balloons, such as OPN NC (SIS Medical, Switzerland) which could be inflated till 35-40 ATM, usually for about 30-60 seconds. Moreover, Angiosculpt (AngioScore, Inc.), a semi-compliant balloon covered by three nitinol coils, have been recently developed and represents a sort of evolution of cutting balloon with lower profile and higher number of cuts by millimeter of plaque.

In common everyday practice, complex fibro-calcific coronary lesions still represent a challenge for the interventional cardiologist and commonly require adjunctive techniques and devices to facilitate successful PCI. However, only correct and experienced employment of such devices could lower the risk of complications, especially more catastrophic ones. Therefore, all the above descripted devices should be available in cath lab and specific training programs should be attended by single operators.

\section{RADIATION EXPOSURE IN THE CATH LAB: FACING THE PUBLIC ENEMY}

Over the past decade, CTO interventions progressively spread all over the world leading to an increase awareness of radiation exposure. CTO procedures are quite often long and complex procedures with associated longer fluoroscopy times, as reported in several registries ${ }^{[11]}$. However, the absence, among interventional cardiologists, of consciousness of radiation injuries lead to development of a position paper about medical radiation in cardiovascular imaging ${ }^{[26]}$. Radiation-associated complications can be categorized as deterministic (which have a threshold above which injury occurs, e.g., skin injury) and stochastic (that have no threshold for injury to occur, e.g. cancer, infertility). Nowadays, the accepted threshold for skin injuries is 5 Gray, so operators should follow the so-called ALARA rule (radiation as low as reasonably acceptable) in order to minimize radiation injuries to the patient. Therefore, moving from CTO procedures, some tricks to reduce radiation exposure are now commonly followed in every day practice: (1) reduction of the fluoroscopy frame rate from 15/s to 7.5/s (probably the most effective way); (2) use of fluoro-store function; and (3) optimization of $\mathrm{x}$-ray tube collimation.

\section{PROCEDURAL COMPLICATIONS: LESSONS LEARNED FROM CTO PROCEDURES}

In the setting of CTO interventions, the incidence of complication is usually higher than everyday $\mathrm{PCI}^{[27]}$. Perforation, acute vessel thrombosis and device entrapment are the most common cardiac complications and are more common during retrograde procedures. Moreover, extracardiac complications, such as arterial embolization, radiation injury, contrast induced nephropathy and vascular access complication should be taken into account when performing both CTO procedures and everyday PCI.

In the everyday PCI setting, acute vessel thrombosis is the most common cardiac complication and could be caused by five main mechanisms: dissection, new thrombus formation, no reflow, inadvertent air injection and vasospasm ${ }^{[28]}$. Coronary dissection usually happens in long, complex and calcific lesions and rarely cause vessel closure. Moreover, in the vast majority of cases, a guidewire could be advanced throughout the vessel true lumen and this complication is easily managed by stent deployment. Seldom, acute coronary dissection followed by abrupt vessel closure could be caused by sub intimal tracking of hydrophilic guidewire with some difficulties to re-gain vessel true lumen and perform PCI. In such cases, the use of stiffer and/or easily directing CTO guidewires in experienced hands could be very useful even in combination with dissection and re-entry techniques.

Nowadays, arterial perforation is still the most common interventional cardiologist's nightmare and is not only restricted to CTO procedures. The incidence of coronary artery perforation is less than $1 \%$, but is a very 
Table 4. Ellis classification of coronary perforation ${ }^{[30]}$

\begin{tabular}{ll}
\hline Ellis class & \multicolumn{1}{c}{ Definition } \\
\hline I & Extraluminal crater without extravasation \\
II & Pericardial or myocardial blushing \\
III & Width of perforation $\geq 1 \mathrm{~mm}$ with contrast streaming and cavity spilling \\
\hline
\end{tabular}

catastrophic complication which could lead to sudden cardiac tamponade or acute myocardial infarction ${ }^{[29]}$. Aggressive predilation or postdilation, usually in more calcified lesions, could determine large vessel perforations. Indeed, one of the most predictive factors for large vessel perforation is a high balloon-to-artery ratio $>1.2$ combined with a high inflation pressure ${ }^{[29]}$. Moreover, rotational aterectomy is another common cause of such complication.

Ellis score is usually used to grade the severity of such perforation and Ellis grade III (defined as contrast extravasation from $>1 \mathrm{~mm}$ perforation) is associated with the highest mortality ${ }^{[30]}$ [Table 4]. However, coronary perforation severity and subsequent management is strongly affected by clinical scenario and perforation site.

In any case of proximal vessel perforation without jet extravasation (Ellis 1), treatment is limited to careful observation for 15-30 min and no further actions are needed if does not increase. In contrast to previous common practice, now is strongly avoided to reverse heparin with protamine until all equipments are removed from coronary artery. When even minimum pericardial or myocardial blushing occurs, the optimal strategy is to inflate a balloon for about $10 \mathrm{~min}$ at low pressure over the site of perforation to stop the flow. To avoid prolonged ischemia during this phase, some operators suggested the "microcatheter distal perfusion technique", which consist of placing over another guidewire a microcatheter distal to perforation in order to inject patient's blood. When balloon inflation does not achieve vessel sealing, a covered stent should be placed in the site of perforation from the same catheter or by using the so-called "ping-pong technique". Indeed, in case of consistent jet extravasation, removal of balloon and subsequent deliver of covered stent could determine massive blood loss. Moreover, only recently developed covered stents shows compatibility with 6F GC (PK Papyrus, Biotronik, Berlin, Germany) but they still not allow coexistence with balloon shaft, thus determining the need for GC replacement. In such cases, this CTO derived technique conveys the use of a second GC to engage the coronary ostium while the first is withdraw few millimeters without deinflate balloon at perforation site. Therefore, during rapid balloon deinflation and reinflation, a second guidewire is placed distally. Such balloon is finally deinflated and retrieved only while covered stent is delivered at the site of perforation.

In the setting of CTO interventions, routine use of heavier, polymer jacketed and tapered guidewires results in a higher incidence of distal perforation related to wire manipulation. However, this complication could even happen during daily PCI when a CTO (or simply a workhorse hydrophilic) guidewire is chosen to cross a complex lesion. When distal perforation happen, proximal prolonged balloon inflation should be considered as first line treatment. Nevertheless, a higher dose of heparin is usually administered during CTO or complex PCI thus lowering the success of such strategy. In past decades, complete sealing of distal perforation was usually obtained with local injection of subcutaneous fat through an inflated over-the-wire balloon in order to prevent spreading of such material in other coronary arteries or systemic circulation. Nowadays, micro detachable coils for neuroradiology interventions have been developed and could be safely used to seal distal coronary perforation. Indeed, such coils are 0.010 compatible and could be easily delivered through all microcatheters commonly used in cathlab, which show an inner diameter between 0.015 (Nhancer Pro X, IMDS, The Netherlands) and 0.018 (Finecross, Terumo, Japan). The best option is a recently described technique, called "balloon-microcatheter technique" which allow fast and easy sealing of distal coronary perforation in everyday setting ${ }^{[31]}$. After proximal balloon inflation, they suggest to advance 
a microcatheter over a second wire beyond the inflated balloon (during very short balloon deflation) in order to facilitate distal micro-coils delivering. However, it should be considered that, during standard PCI performed by 6F GC, only Finecross (Terumo, Japan) and Nhancer Pro X (IMDS, The Netherlands) microcatheters could be advanced parallel to the inflated balloon without increase GC inner diameter. One or more micro-coils are then delivered through the microcatheter and repeated checking of distal sealing may be done during short balloon inflations.

In everyday practice, coronary perforation occurs quite infrequently when compared to CTO procedures, but still carry out a higher incidence of adverse outcome. A complete knowledge and cath lab avalaibility of dedicated devices, such as micro-coils and covered stent is essential. In case of such complication even more important is a step-by-step approach together with employment of CTO derived rescue methods, such as "ping-pong" or "balloon-microcatheter" techniques, which could improve patient's survival.

\section{CONCLUSION}

CTO intervention is a rapidly evolving area and is commonly considered the last frontier of interventional cardiology. Specific equipment and techniques showed a rapid evolution in last decade, thus increasing procedural success even in less experienced centers. Nowadays, global knowledge of CTO tools is widespread and they have become a strong and precise weapon in interventional cardiologist's hand to face obstacles encountered in daily PCI scenario.

\section{DECLARATIONS}

\section{Authors' contributions}

All authors have contributed equally to the article.

\section{Availability of data and materials}

Not applicable.

\section{Financial support and sponsorship}

None.

\section{Conflicts of interest}

All authors declared that there are no conflicts of interest.

\section{Ethical approval and consent to participate}

Not applicable.

\section{Consent for publication}

Not applicable.

\section{Copyright}

The Author(s) 2019.

\section{REFERENCES}

1. Sianos G, Werner GS, Galassi AR, Papafaklis MI, Escaned J, et al. Recanalisation of chronic total coronary occlusions: 2012 consensus document from the Euro CTO club. EuroIntervention 2012;8:139-45.

2. Anderson HV, Shaw RE, Brindis RG, Hewitt K, Krone RJ, et al. A contemporary overview of percutaneous coronary interventions. The american college of cardiology-national cardiovascular data registry (ACC-NCDR). J Am Coll Cardiol 2002;39:1096-103.

3. Williams DO, Holubkov R, Yeh W, Bourassa MG, Al-Bassam M, et al. Percutaneous coronary intervention in the current era compared with 1985-1986: the national heart, lung, and blood institute registries. Circulation 2000;102:2945-51.

4. Suero JA, Marso SP, Jones PG, Laster SB, Huber KC, et al. Procedural outcomes and long-term survival among patients undergoing 
percutaneous coronary intervention of a chronic total occlusion in native coronary arteries: a 20-year experience. J Am Coll Cardiol 2001;38:409-14.

5. Galassi AR, Boukhris M, Toma A, Elhadj Z, Laroussi L, et al. Percutaneous coronary intervention of chronic total occlusions in patients with low left ventricular ejection fraction. JACC Cardiovasc Interv 2017;10:2158-70.

6. Jang WJ, Yang JH, Choi SH, Song YB, Hahn JY, et al. Long-term survival benefit of revascularization compared with medical therapy in patients with coronary chronic total occlusion and well-developed collateral circulation. JACC Cardiovasc Interv 2015;8:271-9.

7. Henriques JP, Hoebers LP, Ramunddal T, Laanmets P, Eriksen E, et al. Percutaneous intervention for concurrent chronic total occlusions in patients with STEMI: the EXPLORE trial. J Am Coll Cardiol 2016;68:1622-32.

8. Mashayekhi K, Nührenberg TG, Toma A, Gick M, Ferenc M, et al. A randomized trial to assess regional left ventricular function after stent implantation in chronic total occlusion: the REVASC trial. JACC Cardiovasc Interv 2018;11:1982-91.

9. Werner GS, Martin-Yuste V, Hildick-Smith D, Boudou N, Sianos G, et al. A randomized multicentre trial to compare revascularization with optimal medical therapy for the treatment of chronic total coronary occlusions. Eur Heart J 2018;39:2484-93.

10. Walsh $\mathrm{S}$ on the behalf of Consistent CTO Investigators. CONventional antegrade vs. Sub-Intimal SYNERGY sTENTing in Chronic Total Occlusions. EuroPCR 2018. Available from: https://www.pcronline.com/Cases-resources-images/Resources/Course-videosslides/2018/Hotline-coronary-interventions. [Last accessed on 10 Apr 2019]

11. Galassi AR, Tomasello SD, Reifart N, Werner GS, Sianos G, et al. In-hospital outcomes of percutaneous coronary intervention in patients with chronic total occlusion: insights from the ERCTO (European Registry of Chronic Total Occlusion) registry. EuroIntervention 2011;7:472-9.

12. Thompson CA, Jayne JE, Robb JF, Friedman BJ, Kaplan AV, et al. Retrograde techniques and the impact of operator volume on percutaneous intervention for coronary chronic total occlusions an early U.S. experience. JACC Cardiovasc Interv 2009;2:834-42.

13. Wilson WM, Walsh SJ, Yan AT, Hanratty CG, Bagnall AJ, et al. Hybrid approach improves success of chronic total occlusion angioplasty. Heart 2016;102:1486-93.

14. Maeremans J, Spratt JC, Knaapen P, Walsh S, Agostoni P, et al. Towards a contemporary, comprehensive scoring system for determining technical outcomes of hybrid percutaneous chronic total occlusion treatment: The RECHARGE score. Catheter Cardiovasc Interv 2018;91:192-202.

15. Christopoulos G, Kandzari DE, Yeh RW, Jaffer FA, Karmpaliotis D, et al. Development and validation of a novel scoring system for predicting technical success of chronic total occlusion percutaneous coronary interventions: The PROGRESS CTO (Prospective Global Registry for the Study of Chronic Total Occlusion Intervention) Score. JACC Cardiovasc Interv 2016;9:1-9.

16. Smith SC Jr, Dove JT, Jacobs AK, Kennedy JW, Kereiakes D, et al. ACC/AHA guidelines of percutaneous coronary interventions (revision of the 1993 PTCA guidelines)-executive summary. A report of the American college of cardiology/American heart association task force on practice guidelines (committee to revise the 1993 guidelines for percutaneous transluminal coronary angioplasty). J Am Coll Cardiol. 2001;37:2215-39.

17. Morino Y, Abe M, Morimoto T, Kimura T, Hayashi Y, et al. Predicting successful guidewire crossing through chronic total occlusion of native coronary lesions within 30 minutes: the J-CTO (Multicenter CTO Registry in Japan) score as a difficulty grading and time assessment tool. JACC Cardiovasc Interv 2011;4:213-21.

18. Jolly SS, Yusuf S, Cairns J, Niemelä K, Xavier D, et al. Radial versus femoral access for coronary angiography and intervention in patients with acute coronary syndromes (RIVAL): a randomised, parallel group, multicentre trial. Lancet 2011;377:1409-20.

19. Burzotta F, Trani C, Tommasino A, Giammarinaro M, De Vita M, et al. Radial approach for CTO lesions: acute, long term results and impact of learning curve. EuroInteventions 2011;7:260

20. Mamas MA, Fath-Ordoubadi F, Fraser DG. Distal stent delivery with GuideLiner catheter: first in man experience. Catheter Cardiovasc Interv 2010;76:102-11.

21. Fujita S, Tamai H, Kyo E, Kosuga K, Hata T, et al. New technique for superior guiding catheter support during advancement of a balloon in coronary angioplasty: the anchor technique. Catheter Cardiovasc Interv 2003;59:482-8.

22. Ali M, Yagoub H, Ibrahim A, Ahmed M, Ibrahim M, et al. Anchor-balloon technique to facilitate stent delivery via the GuideLiner cathter in percutaneous coronary interventions. Future Cardiol 2018;14:291-9.

23. Oreglia JA, Garbo R, Gagnor A, Gasparini GL. Dual lumen microcatheters for complex percutaneous coronary interventions. Cardiovasc Revasc Med 2018;19:298-305.

24. Patel SM, Pokala NR, Menon RV, Kotsia AP, Raja V, et al. Prevalence and treatment of "balloon-uncrossable" coronary chronic total occlusions. J Invasive Cardiol 2015;27:78-84.

25. Brinton TJ. Lithoplasty for treatment of calcified coronary disease the results of the DISRUPT CAD study. EuroPCR 2017.

26. Picano E, Vano E, Rehani MM, Cuocolo A, Mont L, et al. The appropriate and justified use of medical radiation in cardiovascular imaging: A position document of the ESC associations of cardiovascular imaging, percutaneous cardiovascular interventions and electrophysiology. Eur Heart J 2014;35:665-72.

27. Brilakis ES, Banerjee S, Karmpaliotis D, Lombardi WL, Tsai TT, et al. Procedural outcomes of chronic total occlusion percutaneous coronary intervention: a report from the NCDR (National Cardiovascular Data Registry). JACC Cardiovasc Interv 2015;8:245-53.

28. Giannini F, Candilio L, Mitomo S, Ruparelia N, Chieffo A, et al. A practical approach to the management of complications during percutaneous coronary intervention. JACC Cardiovase Interv 2018;11:1797-810.

29. Stankovic G, Orlic D, Corvaja N, Airoldi F, Chieffo A, et al. Incidence, predictors, in-hospital, and late outcomes of coronary artery perforations. Am J Cardiol 2004;93:213-6.

30. Ellis SG, Ajluni S, Arnold AZ, Popma JJ, Bittl JA, et al. Increased coronary perforation in the new device era. Incidence, classification, management, and outcome. Circulation 1994;90:2725-30.

31. Garbo R, Oreglia JA, Gasparini GL. The Balloon-Microcatheter technique for treatment of coronary artery perforations. Catheter Cardiovasc Interv 2017;89:E75-83. 